Maurer School of Law: Indiana University

Digital Repository @ Maurer Law

$12-2018$

\title{
Using the EngagedMD Multimedia Platform to Improve Informed Consent for Ovulation Induction, Intrauterine Insemination, and In Vitro Fertilization
}

Jody L. Madeira

Indiana University Maurer School of Law, jmadeira@indiana.edu

Jennifer Rehbein

Wright State University

Mindy S. Christianson

Johns Hopkins University

Miryoung Lee

University of Texas Health Science Center at Houston

Follow this and additional works at: https://www.repository.law.indiana.edu/facpub

1 Preston Parry

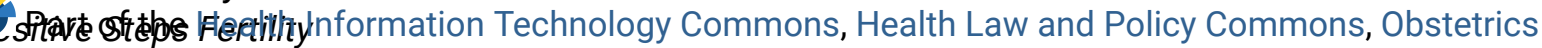

and Gynecology Commons, Reproductive and Urinary Physiology Commons, Science and Technology Law

Commons, and the Women's Health Commons

See next page for additional authors

\section{Recommended Citation}

Madeira, Jody L.; Rehbein, Jennifer; Christianson, Mindy S.; Lee, Miryoung; Parry, J. Preston; Pennings, Guido; and Lindheim, Steven R. MD, "Using the EngagedMD Multimedia Platform to Improve Informed Consent for Ovulation Induction, Intrauterine Insemination, and In Vitro Fertilization" (2018). Articles by Maurer Faculty. 2978.

https://www.repository.law.indiana.edu/facpub/2978

This Article is brought to you for free and open access by the Faculty Scholarship at Digital Repository @ Maurer Law. It has been accepted for inclusion in Articles by Maurer Faculty by an authorized administrator of Digital Repository@ Maurer Law. For more information, please contactrvaughan@indiana.edu. 


\section{Authors}

Jody L. Madeira, Jennifer Rehbein, Mindy S. Christianson, Miryoung Lee, J. Preston Parry, Guido Pennings, and Steven R. Lindheim MD 


\title{
Using the EngagedMD multimedia platform to improve informed consent for ovulation induction, intrauterine insemination, and in vitro fertilization
}

\author{
Jody Lyneé Madeira, J.D., Ph.D., ${ }^{a}$ Jennifer Rehbein, M.D., ${ }^{b}$ Mindy S. Christianson, M.D., ${ }^{c}$ Miryoung Lee, Ph.D., ${ }^{d}$ \\ J. Preston Parry, M.D., ${ }^{e}$ Guido Pennings, Ph.D., ${ }^{\dagger}$ and Steven R. Lindheim, M.D., M.M.M. ${ }^{b}$ \\ a Maurer School of Law, Indiana University, Bloomington, Indiana; ${ }^{b}$ Department of Obstetrics and Gynecology, Wright \\ State University, Boonshoft School of Medicine, Dayton, Ohio; ' Department of Gynecology and Obstetrics, Johns \\ Hopkins University School of Medicine, Baltimore, Maryland; 'd Department of Epidemiology, Human Genetics, and \\ Environmental Sciences, University of Texas Health Science Center at Houston, School of Public Health, Brownsville, \\ Texas; ${ }^{e}$ Positive Steps Fertility, Madison, Mississippi; ${ }^{f}$ Bioethics Institute Ghent, Department of Philosophy and Moral \\ Science, Ghent University, Blandijnberg, Gent, Belgium
}

Objective: To study patient and provider feedback on how a multimedia platform (EngagedMD) helps patients to understand the risks and consequences of in vitro fertilization (IVF), ovulation induction (OI), and intrauterine insemination (IUI) treatments and the impact of the informed consent process.

Design: Prospective survey study.

Setting: IVF units in the United States.

Patient(s): Six-thousand three-hundred and thirty-three patients who viewed the multimedia platform before IVF or OI-IUI treatment at 13 U.S. IVF centers and 128 providers.

Intervention(s): Quantitative survey with 17 questions.

Main Outcome Measure(s): Assessment of the impact of a multimedia platform on patient anxiety, comprehension, and satisfaction and provider/nurse feedback related to the informed consent process.

Result(s): The survey was completed by 3,097 respondents (66\% IVF treatment; 34\% OI-IUI treatment) and 44 providers. Overall, 93\% felt the media platform was intuitive, and 90\% and 95\% felt it had appropriate duration and detail, respectively. Most agreed/strongly agreed it better prepared them to consent (88\%), increased their comfort in pursuing treatment (77\%) and increased their satisfaction with their care (83\%). Compared with the OI-IUI group, statistically significantly more participants who viewed the IVF media platform strongly agreed that the comprehension questions reinforced key concepts (47\% vs. 40\%), educated them about treatment risks (55\% vs. $44 \%$ ), helped them ask providers informed questions (45\% vs. 36\%), and better prepared them to sign consent forms (46\% vs. 37\%). Overall, 63\% of providers felt that the media platform improved patient learning, made patients more accountable, and standardized information dissemination.

Conclusion(s): The EngagedMD media platform improves patient knowledge, satisfaction, and control over medical decision making and better prepares patients to give informed consent. Furthermore, it is well-liked by providers and is easily implemented. (Fertil Steril ${ }^{\circledR}$ 2018;110:1338-46. (C2018 by American Society for Reproductive Medicine.)

El resumen está disponible en Español al final del artículo.

Key Words: Assisted reproductive technology, informed consent, in vitro fertilization, multimedia platform

Discuss: You can discuss this article with its authors and other readers at https://www.fertstertdialog.com/users/16110-fertilityand-sterility/posts/37730-26186

Received April 20, 2018; revised August 19, 2018; accepted August 20, 2018

J.L.M. has nothing to disclose. J.R. has nothing to disclose. M.S.C. has nothing to disclose. M.L. has nothing to disclose. J.P.P. has nothing to disclose. G.P. has nothing to disclose. S.R.L. has nothing to disclose. None of the authors have any financial or business relationship with EngagedMD, nor any other commercial provider of informed consent or patient multimedia education software.

Supported by faculty research support grant of $\$ 27,500$ by Indiana University (to J.L.M.).

Reprint requests: Steven R. Lindheim, M.D., M.M.M., 128 Apple Street, Suite 3800 Weber CHE, Dayton, Ohio 45409 (E-mail: steven.lindheim@wright.edu).

Fertility and Sterility® Vol. 110, No. 7, December 2018 0015-0282/ $\$ 36.00$

Copyright @2018 American Society for Reproductive Medicine, Published by Elsevier Inc.

https://doi.org/10.1016/j.fertnstert.2018.08.045 
I nformed consent within the context of assisted reproduction technology (ART) poses unique ethical, medical, and legal challenges because these treatments are intended to create offspring. The risks, benefits, side effects, and alternatives of ART often bear little resemblance to those in other practice areas-including the legal consequences of establishing and relinquishing parental rights. With each medical advance in ART, informed consent for the associated therapies becomes more difficult, and the discussions grow increasingly complex $(1,2)$.

The American Society for Reproductive Medicine (ASRM) has created a model template for informed consent (3). However, many reproductive endocrinologists, mental health professionals, and attorneys have expressed concern over whether patients actually understand and balance ART's risks, benefits, side effects, and alternatives. Furthermore, often patients find the ART consent process overwhelming or disregard it as unimportant, which undermines their recall and comprehension (3-5).

In other disciplines, medical practitioners have employed a variety of multimedia patient education and consent tools to improve patients' comprehension $(1,2)$. These tools range from DVDs to narrated computer applications and computer tutorials complete with quizzes, which can be accessed in clinical settings or from personal computers or mobile devices (4). Older studies of multimedia aids have yielded equivocal results regarding their superiority to traditional paper consent materials because poorly designed aids (e.g., those that are tedious or too long) can negatively impact patient education (4-7). More recent randomized studies have linked multimedia interventions to greater patient enjoyment; improved patient knowledge, comprehension, and recall; improved physician-patient relationships; lower anxiety; and faster learning $(8,9)$. The interactive format of multimedia interventions has been found to increase patient comprehension and enjoyment (1). These presentations have also been described as ensuring consistency across providers and patients, potentially decreasing the feeling that consent is a bureaucratic routine, and simultaneously encouraging patients to be more involved with their care (8).

EngagedMD, a commercially available multimedia platform, was designed to supplement communication among physicians, nurses, support staff, and patients, with data collected from multiple representatives of each of these stakeholders via online surveys and in-person and phone interviews. Using that information, a beta (usable prototype) version of the platform was launched in December 2014.

This particular media platform allows patients to watch customizable educational video modules that cover the topics of in vitro fertilization (IVF), ovulation induction (OI), and intrauterine insemination (IUI) treatments, followed by short comprehension quizzes. The modules were developed in collaboration with each of the stakeholder groups to create outlines of what topics should be covered. Using established consent forms from the Society for Assisted Reproductive Technology (SART), a script was created covering each topic, and live shots were filmed and paired with a professional voiceover reading the information that physician consultants deemed necessary in solicited feedback.
Before a module went live, the physicians at each practice reviewed and accepted it; if necessary, they could make adjustments to the module to ensure alignment with the practice's needs. The providers could track the patients' progress and quiz responses to ascertain where the patients might need additional information. The objective of our study was to examine the impact of a multimedia platform on patient anxiety, comprehension, and satisfaction as well as provider/nurse feedback related to the informed consent process.

\section{MATERIALS AND METHODS}

This prospective survey study was reviewed and approved by the Indiana University-Bloomington human subjects institutional review board, and the study was in compliance with privacy act guidelines (5). Links to a 17-question electronic survey were sent to English-speaking patients whose providers had assigned them to the multimedia platform before undergoing OI-IUI or IVF at one of 13 fertility clinics implementing the multimedia platform from October 2015 to March 2017. All patients who completed the media platform modules (IVF or OI-IUI) were given the option to complete the survey regardless of completion of treatment. By March 2017, a total of 13 IVF programs in the United States had implemented the multimedia platform into their patient education process. Three were academic programs, and 10 were private clinics, of which five were located on the East Coast, five in the Midwest, and three on the West Coast. The practice sizes were diverse: seven performed $<500$ IVF cycles/year, two performed between 500 and 999 IVF cycles/year, and four performed $>1,000$ IVF cycles/year. Each program implemented the media platform at its own discretion (either after the initial consult or before/after the patient's teaching/ educational session).

The survey was not originally created for the purpose of publishing the results; rather, it was designed to assess patient and provider/nurse feedback and opinions regarding the media platform's impact on perceived comprehension and satisfaction as related to the informed consent process. For this reason, obtaining demographic information from respondents was not part of the initial design. The Likert item responses were scaled as follows: 1, strongly disagree; 2, disagree; 3 , neutral; 4, agree; and 5, strongly agree. The questionnaires also included both closed and open-ended questions that allowed for comments.

\section{Multimedia Platform}

The multimedia platform consists of customizable educational video modules 5 to 7 minutes in length covering IVF, OI, and IUI treatments written and voiced over in English at a 10th grade comprehension level (Fig. 1). To use the platform, both the patient and the practice need access to a computer, phone, or tablet with broadband Internet. There are no other technical requirements. Each video is followed by a brief matching quiz, during which an incorrect answer triggers a pop-up screen with the correct answer. The IVF modules (including quiz questions) can be completed in approximately 1 hour and 20 minutes; the OI-IUI module can be completed in 50 minutes. Patients also can submit questions to their 


\section{FIGURE 1}

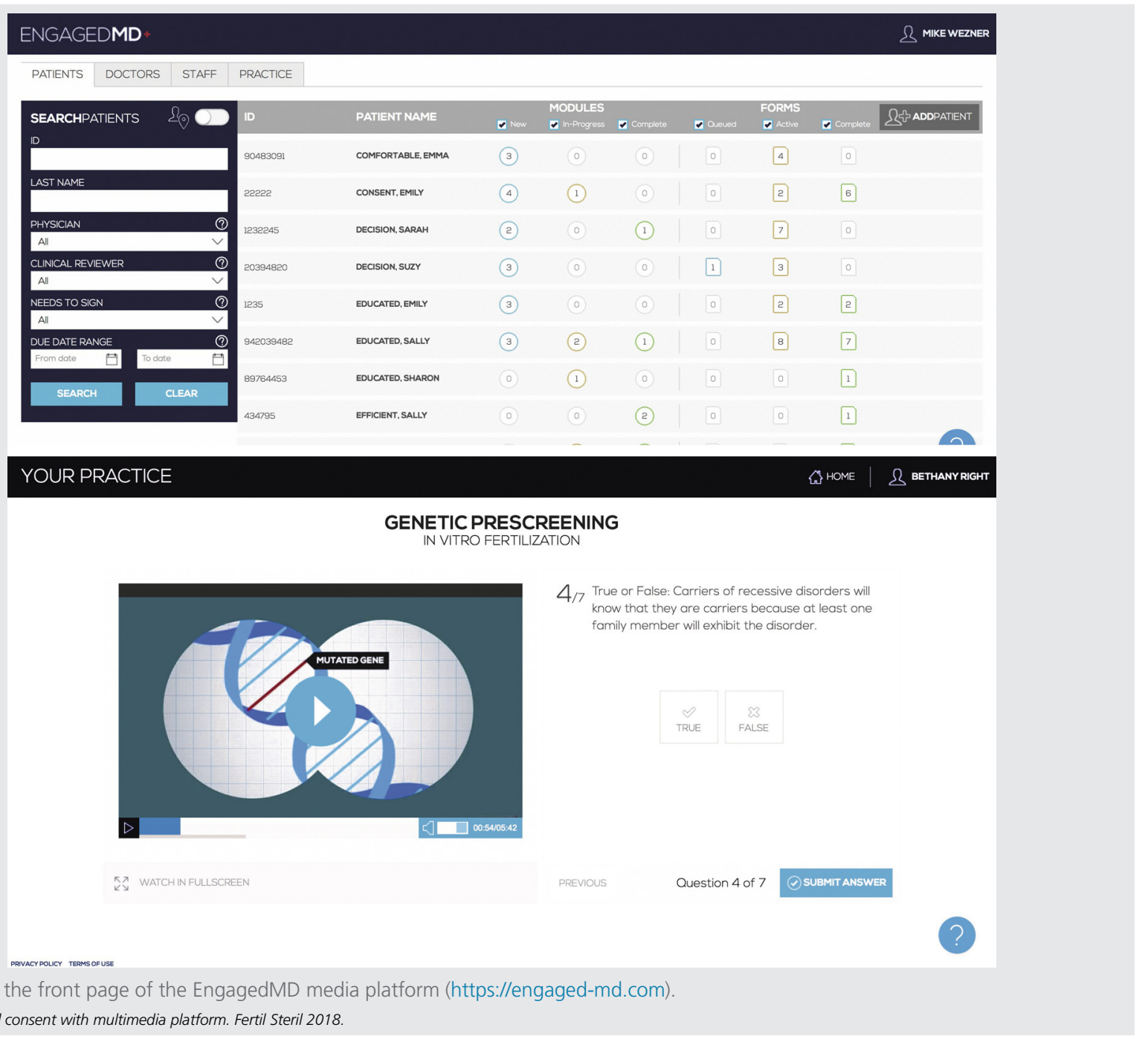

Screenshot of the front page of the EngagedMD media platform (https://engaged-md.com)

Madeira. Informed consent with multimedia platform. Fertil Steril 2018.

medical teams, who can see the patients' completion progress, quiz results, and questions through a "backdoor." This allows providers to customize their consent conversations to the patients' individual needs. After completing the media platform, the patients can either sign hard copies or e-sign electronic copies of informed consent documents (specific to each IVF program) before initiating treatment, but the workflow for implementing affirmation of consent is program specific (Supplemental Data, available online).

During platform design and development, the company consulted (and continues to consult) with attorneys who specialize in ART to ensure that its content is legally accurate and meets the state law requirements in the states where the clients are located. (State laws rarely regulate matters such as embryo disposition, with notable exceptions including Louisiana and Arizona.) Since the initial launch, the platform has been continually revised based on user feedback to ensure its alignment with each practice's needs.

Moreover, it is generally accepted that electronic signatures and records have legal force in clinical research and medical treatment. The federal E-SIGN Act gives elec- tronic signatures legal force if all contracting parties choose to use electronic documents and electronic signatures. A prior "model" law, the Uniform Electronic Transactions Act ("UETA") (widely adopted in 47 states, the District of Columbia, and the U.S. Virgin Islands), stated that when a signature or record is legally required, an electronic version can be used when the parties agree to use electronic forms. Records of electronic signatures must be kept under both E-SIGN Act and UETA. Moreover, in clinical trials, the federal Office for Human Research Protections and the U.S. Food and Drug Administration regulations permit the use of electronic signatures when written informed consent is required.

\section{Patients}

In all, 14,028 patients completed the media platform modules during the time period, and 6,333 patients/partners (45.1\%) completed the survey from 13 fertility clinics. Because some data were missing for five key survey questions, we decided to include a total of 3,097 patients/partners $(49 \%$, of 6,333 


\section{TABLE 1}

\section{Survey questions and responses.}

\section{Variable}

Did the program answer any questions that you otherwise would have had to ask your medical team?

No, it did not answer any questions.

Yes, it answered one or a few questions.

Yes, it answered many questions.

Did you like learning about your procedure from the elearning system?

No

Yes

Do you feel that the educational videos you saw as part of this program were a helpful addition to your consultations with your medical team?

No

Yes

How important is it that you are properly educated about your care?

Not at all important

Not important

Neutral

Important

Very Important

Learning about my procedure from the eLearning system made me:

Less satisfied with my care.

Neither more or less satisfied with my care.

More satisfied with my care.

The comprehension questions helped reinforce key concepts.

Strongly disagree

Disagree

Neutral

Agree

Strongly agree

The software was intuitive to use.

Strongly disagree

Disagree

Neutral

Agree

Strongly agree

The level of detail in the videos was:

Not detailed enough.

The appropriate level of detail.

Too detailed.

The videos were:

Too short.

The appropriate length for my need.

Too long.

The eLearning module...

Educated me about the risks associated with treatment.

Strongly disagree

Disagree

Neutral

Madeira. Informed consent with multimedia platform. Fertil Steril 2018. N (\%)

3,097

$179(5.8)$

$1,390(44.9)$

$1,528(49.3)$

3097

$151(4.9)$

$2,946(95.1)$

3,097

$96(3.1)$

$3,001(96.9)$

3,094

$3(0.1)$

$4(0.1)$

$34(1.1)$

$457(14.8)$

$2,599(83.9)$

3,097

$36(1.2)$

$826(26.7)$

$2,235(72.2)$

2,663

38 (1.4)

$40(1.5)$

203 (7.6)

$1,200(45.1)$

$1,182(44.4)$

2,661

37 (1.4)

$20(0.8)$

$132(5)$

1,068 (40.1)

$1,404(52.8)$

2,699

$7(0.3)$

2,421 (89.7)

271 (10)

2,699

60 (2.2)

$2,553(94.6)$

86 (3.2)

2,695

63 (2.3)

$10(0.4)$

$114(4.2)$

\section{Respondent}

Total responses

Patient/partners n (\%)

Patient only n (\%)

$P$ value

IVF

$80(5.2)$

$99(6.4)$

165

$676(43.5)$

749 (48.5)

779 (50.1)

$79(5.1)$

$1,464(94.9)$

$72(4.6)$

$1,482(95.4)$

529

95 (4.6)

1,951 (95.4)

$56(5.3)$

995 (94.7)

$16(1)$

$429(27.8)$

20 (1.3)

397 (25.6)

$1,098(71.2)$

$1,137(73.2)$

$4(0.3)$

$18(1.2)$

$228(14.8)$

16 (1)

229 (14.7)

1,308 (84.2)

47 (4.5)

25 (1.9)

$17(1.3)$

95 (7.2)

$23(1.7)$

108 (8.0)

614 (45.5)

586 (44.6)

591 (43.8)

591 (45)

$15(1.1)$

$7(0.5)$

64 (4.8)

$544(40.5)$

715 (53.2)

$2(0.2)$

$1,225(89.7)$

138 (10.1)

33 (2.42)

1,285 (94.14)

22 (1.7)

13 (1)

$68(5.2)$

$524(39.8)$

689 (52.4)

1,196 (89.7)

133 (10)

27 (2.02)

$1,268(95.05)$

47 (3.44)

39 (2.92)

$30(2.2)$

$6(0.4)$

$52(3.8)$ $237^{a}$
$33(2.5)$
$4(0.3)$
$62(4.7)$
$1(0.1)$

$340^{a}$

$3(0.2)$

$3(0.2)$

20 (1.0)

257 (12.6)

$1,763(86.2)$

$1,997(97.6) \quad 1,004(95.5)$

0 (0)

$1(0.1)$

$14(1.3)$

200 (19)

836 (79.5)

$5(0.4)$
313

$25(1.2)$

535 (26.2)

$1,486(72.6)$

$11(1.1)$ 291 (27.7)

749 (71.3)

$.588^{a}$

23 (1.3)

$27(1.5)$

$130(7.4)$

$751(43.0)$

$817(46.7)$

$.462^{a}$

25 (1.4)

$19(1.1)$

$89(5.1)$

$669(38.4)$

942 (54)

.504

$4(0.2)$

$1,586(89.5)$

$182(10.3)$

.577

36 (2)

$1,672(94.4)$

64 (3.6)

881 (95)

$22(2.4)$

15 (1.6)

$13(1.4)$

73 (8.0)

449 (49.1)

365 (39.9)

$12(1.3)$

$1(0.1)$

$43(4.7)$

399 (43.5)

$462(50.4)$

$3(0.3)$

$835(90.1)$

89 (9.6)

$24(2.6)$
002

$<.001^{a}$
$25(2.7)$

$2(0.2)$

$54(5.8)$ 


\section{TABLE 1}

\section{Continued.}

\begin{tabular}{|c|c|c|c|c|c|c|c|}
\hline \multirow[b]{2}{*}{ Variable } & \multirow[b]{2}{*}{$\begin{array}{l}\text { Total responses } \\
\text { N (\%) }\end{array}$} & \multicolumn{3}{|c|}{ Respondent } & \multicolumn{3}{|c|}{ Procedure } \\
\hline & & $\begin{array}{l}\text { Patient/partners } \\
\text { n (\%) }\end{array}$ & $\begin{array}{l}\text { Patient only } \\
\text { n (\%) }\end{array}$ & $P$ value & $\begin{array}{l}\text { IVF } \\
\text { n (\%) }\end{array}$ & $\begin{array}{l}\text { OI-IUI } \\
\text { n (\%) }\end{array}$ & $P$ value \\
\hline $\begin{array}{l}\text { Agree } \\
\text { Strongly agree }\end{array}$ & $\begin{array}{l}1,128(41.9) \\
1,380(51.2)\end{array}$ & $\begin{array}{l}600(43.9) \\
680(49.7)\end{array}$ & $\begin{array}{l}528(39.8) \\
700(52.8)\end{array}$ & & $\begin{array}{l}688(38.9) \\
975(55.1)\end{array}$ & $\begin{array}{l}440(47.5) \\
405(43.7)\end{array}$ & \\
\hline $\begin{array}{l}\text { Enhanced my ability to ask } \\
\text { informed questions of my } \\
\text { medical team. }\end{array}$ & 2,693 & & & & & & \\
\hline Strongly disagree & $61(2.3)$ & $28(2.1)$ & $33(2.5)$ & $.727^{\mathrm{a}}$ & $35(2)$ & $26(2.8)$ & $<.001^{\mathrm{a}}$ \\
\hline Disagree & $25(0.9)$ & $11(0.8)$ & $14(1.1)$ & & $13(0.7)$ & $12(1.3)$ & \\
\hline Neutral & $232(8.6)$ & $100(7.3)$ & $132(10)$ & & $117(6.6)$ & $115(12.4)$ & \\
\hline Agree & $1,251(46.5)$ & $666(48.8)$ & $585(44.1)$ & & $812(46)$ & $439(47.4)$ & \\
\hline Strongly agree & $1,124(41.7)$ & $561(41.1)$ & $563(42.4)$ & & $790(44.7)$ & $334(36.1)$ & \\
\hline $\begin{array}{c}\text { Enhanced my ability to converse } \\
\text { with my medical team. }\end{array}$ & 2,680 & & & & & & \\
\hline Strongly disagree & $63(2.4)$ & $30(2.2)$ & $33(2.5)$ & $.333^{a}$ & $36(2)$ & $27(2.9)$ & $<.001^{\mathrm{a}}$ \\
\hline Disagree & $28(1)$ & $9(0.7)$ & $19(1.4)$ & & $18(1)$ & $10(1.1)$ & \\
\hline Neutral & $275(10.3)$ & $117(8.6)$ & $158(12.0)$ & & $140(8)$ & $135(14.7)$ & \\
\hline Agree & $1,314(49)$ & $702(51.7)$ & $612(46.3)$ & & $864(49.1)$ & $450(49)$ & \\
\hline Strongly agree & $1,000(37.3)$ & 501 (36.9) & 499 (37.8) & & 703 (39.9) & $297(32.3)$ & \\
\hline $\begin{array}{l}\text { Made me better prepared to sign } \\
\text { my informed consent } \\
\text { documents. }\end{array}$ & 2,671 & & & & & & \\
\hline Strongly disagree & $65(2.4)$ & $29(2.2)$ & $36(2.7)$ & $.971^{\mathrm{a}}$ & $39(2.2)$ & $26(2.8)$ & $<.001^{\mathrm{a}}$ \\
\hline Disagree & $29(1.1)$ & $12(0.9)$ & $17(1.3)$ & & $17(1)$ & $12(1.3)$ & \\
\hline Neutral & $254(9.5)$ & $125(9.3)$ & $129(9.8)$ & & $153(8.7)$ & $101(11)$ & \\
\hline Agree & $1,187(44.4)$ & $617(45.7)$ & $570(43.2)$ & & $747(42.6)$ & $440(48)$ & \\
\hline Strongly agree & $1,136(42.5)$ & $568(42)$ & $568(43)$ & & $799(45.5)$ & $337(36.8)$ & \\
\hline $\begin{array}{l}\text { Made me feel more in control of } \\
\text { my medical decisions. }\end{array}$ & 2691 & & & & & & \\
\hline Strongly disagree & $62(2.3)$ & $26(1.9)$ & $36(2.7)$ & $.410^{\mathrm{a}}$ & $38(2.2)$ & $24(2.6)$ & $.006^{a}$ \\
\hline Disagree & $44(1.6)$ & $18(1.3)$ & $26(2)$ & & $31(1.8)$ & $13(1.4)$ & \\
\hline Neutral & $356(13.2)$ & $185(13.6)$ & $171(12.9)$ & & $217(12.3)$ & $139(15.1)$ & \\
\hline Agree & $1,222(45.4)$ & $644(47.2)$ & $578(43.6)$ & & $791(44.7)$ & $431(46.8)$ & \\
\hline Strongly agree & $1,007(37.4)$ & $491(36)$ & 516 (38.9) & & $693(39.2)$ & $314(34.1)$ & \\
\hline $\begin{array}{l}\text { Made me more comfortable to } \\
\text { pursue treatment. }\end{array}$ & 686 & & & & & & \\
\hline Strongly disagree & $10(1.5)$ & $6(1.6)$ & $4(1.3)$ & $.290^{a}$ & $8(1.7)$ & $2(0.9)$ & $.706^{\mathrm{a}}$ \\
\hline Disagree & $24(3.5)$ & $9(2.5)$ & $15(4.7)$ & & $18(3.8)$ & $6(2.8)$ & \\
\hline Neutral & $122(17.8)$ & $68(18.5)$ & $54(16.9)$ & & $89(18.9)$ & $33(15.4)$ & \\
\hline Agree & $291(42.4)$ & $167(45.5)$ & $124(38.9)$ & & $189(40)$ & $102(47.7)$ & \\
\hline Strongly agree & $239(34.8)$ & $117(31.9)$ & $122(38.2)$ & & $168(35.6)$ & $71(33.2)$ & \\
\hline $\begin{array}{l}\text { Played a part in my decision to } \\
\text { pursue treatment. }\end{array}$ & 671 & & & & & & \\
\hline Strongly disagree & $36(5.4)$ & $18(5)$ & $18(5.7)$ & $.084^{a}$ & $26(5.6)$ & $10(4.8)$ & $.472^{\mathrm{a}}$ \\
\hline Disagree & $93(13.9)$ & $52(14.6)$ & $41(13.1)$ & & $62(13.4)$ & $31(14.8)$ & \\
\hline Neutral & $187(27.9)$ & $111(31.1)$ & $76(24.2)$ & & $128(27.7)$ & $59(28.2)$ & \\
\hline Agree & $197(29.4)$ & $101(28.3)$ & $96(30.6)$ & & $130(28.1)$ & $67(32.1)$ & \\
\hline Strongly agree & $158(23.6)$ & $75(21)$ & $83(26.4)$ & & $116(25.1)$ & $42(20.1)$ & \\
\hline
\end{tabular}

survey questionnaires) in the analysis (Table 1). These key questions included "Did the EngagedMD program answer any questions that you otherwise would have had to ask your medical team?"; "Did you like learning about your procedure from the EngagedMD eLearning system?"; "Do you feel that the educational videos you saw as part of this program were a helpful addition to your consultations with your medical team?"; "How important is it that you are properly educated about your care?"; and "Learning about my procedure from the eLearning system made me [less satisfied with my care/neither more or less satisfied with my care/more satisfied with my care]." In addition, the 41 providers (34\% of 120 survey participants) who responded were included in the analysis. To protect participant confidentiality, each participant was assigned a unique identification (ID) number that was used on all data collection forms, in statistical analyses, and for academic scholarship.

\section{Statistics}

All statistical analyses were conducted using SAS for Windows 9.4 (SAS Institute). The statistical significance level 
for statistical tests was set at $\alpha=.05$ (two-tailed). Participants' descriptive characteristics were presented as numbers and percentages. Categorical data analyses were used to examine the statistically significant associations between participants' types (or treatment types) and participants' comprehension and satisfaction related to the multimedia platform using the chi-square test. For questions with ordinal responses (i.e., strongly disagree to strongly agree), Wilcoxon rank sum tests were used to compare the levels of agreement with the multimedia platform for the informed consent process.

\section{RESULTS}

A total of 3,097 patients/partners (49\% of 6,333 survey questionnaires) who completed the multimedia platforms and answered the five key questions were analyzed, comprising 2,046 (66\%) IVF modules and 1,051 (34\%) OI-IUI treatment modules. Because this study did not track the respondents' progress through medical treatment, including whether they ultimately completed an ART procedure, it is unknown how many or which patients who completed the platform and the survey did not complete a cycle. The completed surveys included 1,554 (50\%) respondents whose partners did not take the survey and 1,543 (50\%) respondents who completed the survey with their partner. In general, the majority of respondents-3,056 (99\%) of 3,097-felt that being properly informed about their care was either important or very important.

Overall, 2,472 (93\%) of 2,661 patients felt the multimedia platform was intuitive to use, 2,421 (90\%) of 2,699 thought it was of an appropriate length, and 2,553 (95\%) of 2,699 found it to have an appropriate level of detail. In addition, 2,382 (89.4\%) of 2,663 patients stated that the comprehension questions helped reinforce key concepts. Also, 2,946 (96\%) of 3,097 respondents liked learning about IVF or OI-IUI treatment from the multimedia platform, and 3,001 (97\%) of 3,097 participants felt its videos were a helpful addition to consultations with their medical team; 1,528 (49\%) of 3,097 participants felt it answered many questions that they otherwise would have asked, and 1,390 (45\%) of 3,097 found that it answered one or a few questions. Furthermore, 2,323 (86\%) of 2,693 patients agreed or strongly agreed that the multimedia platform better prepared them to sign consent documents, $530(77 \%)$ of 686 agreed or strongly agreed that it made them more comfortable pursuing treatment, and 2,229 (83\%) 2,691 agreed or strongly agreed that it improved their satisfaction with their care.

In terms of identifying the most effective information source, 1,542 (55\%) of 2,800 patients ranked the physician consultation highest, while $538(19 \%)$ of 2,800 ranked the multimedia platform as the most valuable. Patients did not find the other sources as valuable; only $266(10 \%)$ of 2,800 participants ranked Internet or website sources most effective, and similar results were observed for inperson nurse training $(262$ [9\%] of 2,800) and printed materials $(192[7 \%]$ of 2,800).

Comparing the IVF and OI-IUI media platforms, no differences were observed regarding the patients' responses to questions about intuitiveness of use, length, level of detail, comfort level with pursuing treatment, or satisfaction with care. Compared with the patients using the OI-IUI media platform, however, significantly more respondents using the IVF media platform strongly agreed that the comprehension questions helped reinforce key concepts ( $47 \%$ vs. $40 \%, P=.002$ ), educated them about treatment risks $(55 \%$ vs. $44 \%$, $P<.001$ ), enhanced their ability to ask informed questions of their medical team (45\% vs. 36\%, $P<.001$ ), better prepared them to sign informed consent forms ( $46 \%$ vs. $37 \%, P<.001$ ), enhanced their control over medical decision making (39\% vs. $34 \%, P=.006)$, were helpful additions to medical team consultations (98\% vs. 96\%, $P=.002$ ), and answered many questions that patients would otherwise have asked their medical team (56\% vs. $37 \%, P<.001)$ (see Table 1). No differences were noted between the patients who used the platform alone and those who used it with partners. Similarly, no clinically relevant differences were noted when stratified by academic versus private clinics, geographic location, or program size (data not shown).

\section{Providers' Perceptions of the Multimedia Platform}

Twenty-six (63\%) of 41 providers or nurses felt that the media platform improved patient learning and understanding, made patients more accountable, made patient education more efficient, and allowed them to standardize and disseminate comprehensive information. Overall, $28(68 \%)$ of 41 felt it saved up to 1 hour per patient that was usually spent addressing patients' questions and answering follow-up phone calls and e-mails. Conversely, 7 (17\%) of 41 felt the media platform had some disadvantages, including generating more patient conversations and questions, necessitating more follow-up responsibilities, and introducing concern over exactly when the platform should be implemented.

\section{DISCUSSION}

Our data suggest that a multimedia platform improves patient education regarding ART treatment, gives patients more control over their medical decision making, and better prepares them to participate in the consent process. Overall, the patients' responses suggested that this media platform may be more beneficial for those undergoing IVF. Furthermore, it is also well-liked by providers and nurses, and is easily implemented.

Although informed consent documents are the most frequently used informational aid, they have several inherent weaknesses. As consent forms are often lengthy, patients might be tempted to skim the documents rather than read them carefully $(9,10)$. Given the complexity of the documents, patients may have trouble deciphering the technical or legal jargon, particularly if they have low literacy or are non-native English speakers (11). Moreover, informed consent is affected by psychosocial factors such as satisfaction, happiness, and anxiety, which can also influence knowledge retention and understanding $(12,13)$.

Multimedia platforms have several potential advantages over informed consent documents, including the incorporation of audio narration along with visual cues, diagrams, 
and animations (4). This allows patients to more deeply explore dynamic treatment processes in a more accurate, engaging, and concise format than static images and/or text. To date, such applications have been more widely developed and used in other medical specialties than in reproductive medicine.

Multimedia interventions can allow patients to customize their educational and consent processes by clicking on prompts to get more detailed information, and the applications can be tailored to fit individual learning styles (7). These tools can incorporate quizzes and other tools that immediately reinforce information and give patients direct feedback. Allowing physicians access to patients' quiz answers can help medical teams to identify confusing topics they can clarify in subsequent conversations $(5,10)$. Multimedia platforms can also improve patients' communication with medical teams through assets that allow patients to submit questions or converse with providers in real time (5). Furthermore, patients can access these platforms when it is most convenient and comfortable, whereas the document-based informed consent process traditionally takes place in a structured medical environment $(4,5)$.

Research concerning multimedia aids has generated mixed results. Some empirical evaluations have concluded that these applications can contribute to more active patient learning and engagement, increased comprehension, and more efficient use of time for patients and providers $(5,6)$; however, other studies have demonstrated equivocal outcomes when comparing multimedia platforms to traditional consent documents.

Cohn and Larson (7) reviewed 980 multimedia informed consent studies that evaluated documents, multimedia tools, and in-person education to assess whether any particular medium facilitated superior patient comprehension; they concluded that no single medium was consistently associated with improved comprehension and that a variety of methods could be most efficacious (7). Randomized clinical trials have also attempted to address these issues. Kass et al. (8) assessed whether a computer-based intervention improved patient comprehension relative to traditional consent documents when describing oncologic early-phase research trials; they found only minimal differences in patient understanding of the trial's purpose and participation benefits when comparing patients who were assigned to a computer-based intervention with those who received documents. Jeste et al. (14) reported that patient satisfaction with informational quality and aid effectiveness was high for both patients who received traditional consent documents $(P=.43)$ and those who received access to a multimedia aid $(P=.47)$.

Still other studies have suggested that face-to-face discussions appear to improve patient understanding more than both multimedia platforms and traditional document consent methods, and that the best approach might be to combine multimedia tools with interpersonal discussion. However, a few studies have documented a negative impact associated with computer-based patient education, including patient complaints that videos are more tedious, unnecessarily long, emotionally distressing, or harder to use as compared to consent documents $(6,15)$.
Finally, several studies have concluded that multimedia platforms are effective educational and consent aids $(9,16-$ 18). A literature review of 66 studies assessing multimedia interventions concluded that such tools were associated with higher patient satisfaction with consent processes, greater patient enjoyment, and improved comprehension (6). Other studies comparing multimedia aids with consent documents found statistically significantly higher comprehension and satisfaction among patients assigned to the multimedia intervention (16-18). Willis (11) found that features of multimedia platforms such as brief quizzes and pop-up screens may allow providers to more easily identify obstacles in patient understanding that traditional documents would not reveal.

These conflicting empirical results must be interpreted with caution as several studies had limitations such as small or unrepresentative samples, poor experimental design, lack of blinding, and demographic differences between groups $(6,15)$. Additionally, it is difficult to meaningfully compare different multimedia interventions with respect to clarity, animated versus photographic visuals, games, and quizzes. There is even disagreement over what constitutes "comprehension" and how it should be measured $(7,9)$, let alone gauging how to overcome challenges such as low literacy and limited health knowledge (9). Studies assess different outcomes and use different analytics or measures. For example, some of them test recall but not patient decision making, or they use cognitive interviewing but not surveys. Finally, little research has assessed the patients' psychological states at the time of consent, or investigated how this factor impacts pretreatment information storage, retention, and recall.

Our study is the first to empirically assess multimedia interventions in ART informed consent processes and to analyze a multimedia platform from both patient and provider perspectives. The multimedia platform assessed in this study appears to have been designed with an eye to avoiding problematic flaws such as overly long or complex videos. $\mathrm{Pa}-$ tients identified several advantages of this multimedia platform, including increased satisfaction (more individualized experiences), efficacy (answering existing questions, better use of patient time), convenience (completion at patient discretion), information delivery (more details about treatment procedures and risks), and improved patient-physician communication (identifying questions to ask, better use of appointment time). Patients' positive experiences may further impact their overall satisfaction with their providers and medical care.

From the providers' and nurses' perspectives, the multimedia platform improved patient learning and understanding, made patients more accountable, enhanced efficient patient education, and provided the ability to standardize and disseminate comprehensive information. From a value perspective, the majority felt it saved up to an hour per patient.

It is noteworthy that the patients evaluated the IVF platform more highly than the OI-IUI platform. This may be because IVF is more complex than OI-IUI, and it requires more explanation to understand. For this reason, patients 
may find the multimedia platform more useful in explaining concepts regarding IVF compared with OI-IUI treatment because it has visual aids depicting the additional procedures such as intracytoplasmic sperm injection, preimplantation genetic diagnosis, or assisted hatching. However, because the study was quantitative rather than qualitative, further research will be needed to explore this relative preference.

This study has several limitations, including the inability to control for patient experiences before using the multimedia platform (such as prior treatment cycles), the lack of a uniform implementation protocol (completing the media platform before versus after a physician consent conversation), and no baseline assessments of patient knowledge regarding the IVF or OI-IUI process. Given that demographic information was not obtained, patients of varying ages (younger populations vs. older populations) may have differing views and preferences regarding multimedia consenting and knowledge; future studies may investigate these differences. In addition, the survey did not assess how many respondents completed the survey and underwent treatment versus how many did not, which may have impacted the survey outcomes. The strengths of our study included the anonymity of the survey responses, which enhanced truthfulness, and the survey's national distribution, which helped to achieve a wide geographic distribution of patient values, attitudes, and experiences.

There is an urgent need for more empirical investigation of the impact of multimedia platforms on patient recall, comprehension, satisfaction, treatment experience, and treatment relationships. We are currently involved in a randomized, controlled trial comparing this media platform with traditional consent documents in IVF and OI-IUI contexts. Future research can clarify other questions, including identifying when patients should complete the multimedia interventions, where they can use the multimedia platform most effectively (at home or in clinical settings), and whether treatment personnel should be available to assist with usage difficulties.

Informed consent in ART presents unique ethical challenges and considerations for patients, partners, and providers. It requires active engagement from all parties but places much of the burden of conveying material information upon professionals. The educational value of the informed consent process is also related to the quality of patient experience. Yet the consent process is too often conceptualized as an adversarial, standardized, impersonal event instead of a helpful ongoing dialogue within a care relationship (5). Multimedia platforms represent an opportunity to improve the delivery of information in ways that accommodate many learning styles; they can increase patient comprehension, comfort, and communication with providers, and ensure that accurate information is delivered in a standardized format, preparing the patients for interpersonal consent conversations $(1,4)$.
In general, the EngagedMD multimedia platform yielded perceived self-reported benefits for both patients and providers/nurses, potentially making the patients better informed and the informed consent processes more efficient. As the process of informed consent evolves, future research must evaluate its impact upon patient recall and comprehension, emotional dynamics, the patient-physician relationship, and the best implementation timing.

\section{REFERENCES}

1. Winter M, Kam J, Nalavenkata S, Hardy E, Handmer M, Ainsworth H, et al. The use of portable video media vs standard verbal communication in the urological consent process: a multicenter, randomized controlled, crossover trial. BJU Int 2016;118:823-8.

2. Michalski A, Stopa M, Miskowiak B. Use of multimedia technology in the doctor-patient relationship for obtaining patient informed consent. Med Sci Monit 2016;22:3994-9.

3. Practice Committee of the American Society for Reproductive Medicine. Revised minimum standards for practices offering assisted reproductive technologies: a committee opinion. Fertil Steril 2014;102:682-6.

4. Madeira JL, Andraka-Christou B. Paper trails, trailing behind: improving informed consent to IVF through multimedia applications. J Law Biosci 2016;3:2-38.

5. Madeira JL. Taking baby steps: how patients and fertility clinics collaborate in conception. Berkeley: University of California Press; 2018.

6. Lewis D. Computer-based approaches to improving patient education: a review of the literature. J Am Med Inform Assoc 1999;6:272-9.

7. Cohn E, Larson E. Improving participant comprehension in the informed consent process. J Nurs Scholarsh 2007;39:273-80.

8. Kass NE, Sugarman J, Medley AM, Fogarty LA, Taylor HA, Daugherty CK, et al. An intervention to improve cancer patients' understanding of earlyphase clinical trials. IRB Ethics Hum Res 2009;31:1-10.

9. Matiasek J, Wynia MK. Reconceptualizing the informed consent process at eight innovative hospitals. Jt Comm J Qual Patient Saf 2008;34:127-37.

10. Schenker $Y$, Meisel A. Informed consent in clinical care: practical considerations in the effort to achieve ethical goals. JAMA 2011;305:1130-1.

11. Willis $\mathrm{G}$. Cognitive interviewing as a tool to improve the informed consent process. J Empir Res Hum Res 2006;1:9-24.

12. Kent $G$. Shared understandings for informed consent: the relevance of psychological research on the provision of information. Soc Sci Med 1996;43: 1517-23.

13. Alsaffar H, Wilson L, Kamdar DP, Sultanov F, Enepekides D, Higgins KM Informed consent: do information pamphlets improve post-operative riskrecall in patients undergoing total thyroidectomy: prospective randomized control study. J Otolaryngol Head Neck Surg 2016;45:1-6.

14. Jeste DV, Palmer BW, Golshan S, Eyler LT, Dunn LB, Meeks T, et al. Multimedia consent for research in people with schizophrenia and normal subjects: a randomized controlled trial. Schizophrenia Bull 2009;35:719-29.

15. McGraw SA, Wood-Nutter CA, Solomon MZ, Maschke KJ, Benson JT, Irwin DE. Clarity and appeal of a multimedia informed consent tool for biobanking. IRB Ethics Hum Res 2012:34:9-19.

16. Rowbotham MC, Astin J, Greene K, Cummings SR. Interactive informed consent: randomized comparison with paper consents. PLOS ONE 2013;8: e58603.

17. Tait AR, Voepel-Lewis T, Moscucci M. Computer information program improves patient understanding in informed consent for cardiac catheterization. J Clin Outcomes Manag 2010;17:10-2.

18. Tait AR, Voepel-Lewis T, Levine R. Using digital multimedia to improve parents' and children's understanding of clinical trials. Arch Dis Child 2015;100: 589-93. 
Uso de la plataforma multimedia EngagedMD para mejorar el consentimiento informado para la inducción de la ovulación, la inseminación intrauterina y la fecundación in vitro

Objetivo: estudiar las opiniones de los pacientes y los proveedores de salud sobre cómo una plataforma multimedia (EngagedMD) ayuda a los pacientes a entender los riesgos y las consecuencias de los tratamientos de fecundación in vitro (FIV), de inducción de la ovulación (IO) y de inseminación artificial (IA) y el impacto del proceso de consentimiento informado.

Diseño: estudio mediante encuesta prospectiva.

Entorno: unidades de FIV en los Estados Unidos.

Paciente(s): 6333 pacientes que vieron la plataforma multimedia antes del tratamiento de FIV o de IO-IA en 13 centros de FIV de EEUU y 128 proveedores de salud.

Intervención(es): encuesta cualitativa con 17 preguntas.

Medida(s) de resultado(s) principal(es): valoración del impacto de una plataforma multimedia sobre la ansiedad, la comprensión y la satisfacción del paciente y opinión del proveedor de salud/enfermera relacionada con el proceso de consentimiento informado.

Resultado(s): la encuesta fue completada 3.097 encuestados (66\% tratamiento FIV; 34\% tratamiento IO-IA) y 44 proveedores de salud. En conjunto, el 93\% encontraron que la plataforma multimedia era intuitiva y el 90\% y el 95\%, respectivamente, encontraron que tenía una duración apropiada y detallada. La mayoría estuvo de acuerdo o muy de acuerdo en que les preparaba para el consentimiento (88\%), en que aumentaba su comodidad para seguir con el tratamiento (77\%) y en que aumentaba su satisfacción con la atención médica (83\%). Comparado con el grupo IO-IA, de una forma estadísticamente significativa, más participantes que vieron la plataforma multimedia de FIV estuvieron muy de acuerdo en que la comprensión de las preguntas reforzó conceptos clave (47\% vs. 40\%), en que les educó sobre los riesgos del tratamiento (55\% vs. 44\%), en que les ayudó a preguntar a sus proveedores de salud cuestiones informadas (45\% vs. 36\%) y en que les preparó mejor para firmar los consentimientos informados (46\% vs. 37\%). En general, el 63\% de los proveedores de salud sintieron que la plataforma multimedia mejoró el aprendizaje de los pacientes, responsabilizó más a los pacientes, y estandarizó la difusión de la información.

Conclusión(es): La plataforma multimedia EngagedMD mejora en los pacientes el conocimiento, la satisfacción y el control sobre la toma de decisiones médicas y los prepara mejor para otorgar el consentimiento informado. Además, es muy apreciada por los proveedores de salud y fácilmente implementada de los pacientes. 